\title{
ERRATUM
}

T. Fujimori $\cdot$ S. Yamada $\cdot$ H. Yasui $\cdot$ H. Sakurai

Y. In · T. Ishida

\section{Orally active antioxidative copper(II) aspirinate: synthesis, structure characterization, superoxide scavenging activity, and in vitro and in vivo antioxidative evaluations}

Published online: 8 December 2005

(c) SBIC 2005

\section{J Biol Inorg Chem (2005) 10:831-841}

In the legends to both Figs. 4 and 5 the unit mentioned in the first sentence should be micromoles $(\mu \mathrm{M})$ instead of microliters.

In Table $1, v_{\mathrm{Cu}=\mathrm{O}}\left(\mathrm{cm}^{-1}\right)$ should be $v_{\mathrm{C}=\mathrm{O}}\left(\mathrm{cm}^{-1}\right)$.

In the legend of Fig. 1, the letters should be a, b, c, and $\mathrm{d}$ instead of $\mathrm{A}, \mathrm{B}, \mathrm{C}$, and $\mathrm{D}$.

In Table 3, OC should be O-C.

In reference 33 , the number and pages should be 12:655-661 instead of 269:131-136.

The online version of the original article can be found at http:// dx.doi.org/10.1007/s00775-005-0031-3

\footnotetext{
T. Fujimori $\cdot$ S. Yamada $\cdot$ H. Yasui $\cdot$ H. Sakurai $(\bowtie)$ Department of Analytical and Bioinorganic Chemistry, Kyoto Pharmaceutical University, 5 Nacauchi-cho, Yamashina-ku, Kyoto, 607-8414 Japan

E-mail: sakurai@mb.kyoto-phu.ac.jp

Tel.: + 81-75-5954629

Fax: $+81-75-5954753$

Y. In · T. Ishida

Department of Physical Chemistry,

Osaka University of Pharmaceutical Sciences,

4-20-1 Nasahara, Takatsuki, Osaka, 569-1094 Japan
} 